\title{
Trait-dependent response of dung beetle populations to tropical forest conversion at local and regional scales
}

\author{
Elizabeth Nichols,,${ }^{1,2,11}$ María Uriarte, ${ }^{1}$ Daniel E. Bunker, ${ }^{3}$ Mario E. Favila, ${ }^{4}$ Eleanor M. Slade, ${ }^{5}$ Kevina \\ Vulinec, ${ }^{6}$ Trond Larsen, ${ }^{7}$ Fernando Z. Vaz-de-Mello, ${ }^{8}$ Julio Louzada, ${ }^{9}$ Shahid Naeem, ${ }^{1}$ and Sacha H. Spector ${ }^{10}$ \\ ${ }^{1}$ Department of Ecology, Evolution and Environmental Biology, Columbia University, New York, New York 10027 USA \\ ${ }^{2}$ Center for Biodiversity and Conservation, American Museum of Natural History, New York, New York 10024 USA \\ ${ }^{3}$ Department of Biological Sciences, New Jersey Institute of Technology, Newark, New Jersey 07102 USA \\ ${ }^{4}$ Instituto de Ecología, A.C., Xalapa, Veracruz, Mexico \\ ${ }^{5}$ Department of Applied Biology, University of Helsinki, Helsinki, Finland \\ ${ }^{6}$ Department of Agriculture and Natural Resources, Delaware State University, Dover, Delaware 19901 USA \\ ${ }^{7}$ Science and Knowledge Division, Conservation International, Arlington, Virginia 22202 USA \\ ${ }^{8}$ Departamento de Biologia e Zoologia, Instituto de Biociencias, Universidade Federal de Mato Grosso, Cuiabá, Mato Grosso, \\ Brazil 78060-900 \\ ${ }^{9}$ Departamento de Biologia, Universidade Federal de Lavras, Lavras, Minas Gerais, Brazil 78060-900 \\ ${ }^{10}$ Department of Conservation Science, Scenic Hudson, Poughkeepsie, New York 12601 USA
}

\begin{abstract}
Comparative analyses that link information on species' traits, environmental change, and organism response have rarely identified unambiguous trait correlates of vulnerability. We tested if species' traits could predict local-scale changes in dung beetle population response to three levels of forest conversion intensity within and across two biogeographic regions (the Neotropics and Afro-Eurasian tropics). We combined biodiversity surveys, a global molecular phylogeny, and information on three species' traits hypothesized to influence vulnerability to forest conversion to examine (1) the consistency of beetle population response across regions, (2) if species' traits could predict this response, and (3) the cross-regional consistency of trait-response relationships. Most beetle populations declined following any degree of forest conversion; these declines were strongest for Neotropical species. The relationship between traits and population trend was greatly influenced by local and biogeographic context. We discuss the ability of species' traits to explain population trends and suggest several ways to strengthen trait-response models.
\end{abstract}

Key words: body size; context-dependency; extinction risk; extrinsic factors; fitness; functional traits; land use change; population response; Scarabaeinae; trait-based approaches.

\section{INTRODUCTION}

Contemporary species extinctions are seldom random. Rather, species with similar phenotypes or high relatedness tend to exhibit similar responses to environmental change (Turvey and Fritz 2011). Comparative analyses that combine information on species phenotype and phylogeny are important tools in trait-based efforts to understand and predict the distribution and abundance of species across environmental gradients and the threat status of species (Fisher and Owens 2004). However, the detection of strong and consistent associations between animal species' traits and extinction risk or response to environmental change can be rare (Cardillo and Meijaard 2012), in part because existing trait-environment-response relations can be obscured by several factors.

First, analyses that link traits to population-level response metrics may be more successful than those

Manuscript received 15 February 2012; revised 20 July 2012; accepted 16 August 2012. Corresponding Editor: J. A. Rosenheim.

${ }^{11}$ E-mail: lizsnichols@gmail.com linking traits to species-level metrics (e.g., extinction risk), as extinction represents the culmination of a sequence of local population declines, each with potentially distinct trait-environment dynamics (Collen et al. 2011, Yackulic et al. 2011). Second, trait-response relationships may be easier to identify at local spatial scales, where population-level metrics reflect response to localized environmental conditions (Fisher and Owens 2004, Collen et al. 2011). Analyses that aggregate response across broader spatial extents are more likely to encompass multiple, often interacting environmental changes (Isaac and Cowlishaw 2004, Yackulic et al. 2011).

Finally, both the magnitude of population response to localized environmental change and the relationship between species' trait and population response are often highly context dependent (Cardillo et al. 2008, Pocock 2011). For species' traits to be a useful predictor of response to anthropogenic environmental change, interactions between traits and observed local conditions must produce distinct changes in population size that are neither overly idiosyncratic (i.e., site-specific), nor overly generalized across sites with clearly different 
environmental conditions. Such context dependency may occur at regional scales as well (Fritz et al. 2009, Pocock 2011), driven by geographic differences in species composition, exposure to historical extinction filters, or contemporary anthropogenic threats (Lee and Jetz 2011), all of which can influence relationships between traits and response to environmental change (Balmford 1996).

Comparative analyses that target population-level response to environmental change, and contrast responses across biogeographic regions are increasingly powerful tools to determine the context dependency of trait-environment relationships, at both local and regional scales. Such approaches are a crucial step in the determination of the usefulness of existing species' trait data, both for predicting response to anthropogenic change and highlighting where the collection of additional trait data may be necessary (Nylin and Bergstrom 2009, Diamond et al. 2011).

Understanding the ability of existing species' trait information to explain population-level responses to localized environmental change requires addressing three related topics. First, to what degree are local population responses context dependent across individual management practices or biogeographic regions? Second, of the available information on species' traits for a given taxon, which traits are the best predictors of those local population responses to environmental change? Finally, can context dependency in observed trait-population response relationships explain difference in population response across biogeographic regions?

We explored these questions with a global data set of Scarabaeine dung beetle population response to the anthropogenic conversion of lowland tropical forest. We combined information on dung beetle response to forest conversion at three distinct levels of land management intensity, with species' trait information and a molecular phylogeny to explore the possibility of local and regional context dependency in trait-response relationships. To our knowledge, this is the first global assessment of local trait-population response relationships of any taxon.

Dung beetles are a cosmopolitan insect group, highly sensitive to the direct impacts of tropical forest conversion (Nichols et al. 2007) and the indirect effects that conversion has on mammalian fecal resources (Nichols et al. 2009). Beetle fauna in different biogeographical regions have experienced strikingly different climatic and vegetation conditions over evolutionary time, which may contribute to differential sensitivity to the altered environmental conditions that accompany forest conversion. Several studies demonstrate that three dung beetle species' traits are associated with response to tropical forest conversion (i.e., activity period, body size, and nesting strategy; Appendix A). However these traits have never been linked with population-level responses across multiple studies, corrected for phylogenetic autocorrelation, nor evaluated across biogeo- graphic regions with contrasting climatic and ecological histories. Given their demonstrated sensitivity to forest conversion (Nichols et al. 2007) and key functional roles (Nichols et al. 2008), these questions are of broad, practical importance.

\section{Materials And Methods}

Dung beetle surveys

We compiled 24 studies that comparatively sampled dung beetle communities in "intact" moist lowland $(<2000 \mathrm{~m})$ tropical rain forest and neighboring areas of human-modified forest across the Neotropics $(n=18)$, and Afro-Eurasian tropics $(n=6)$ (Appendix B). As several biodiversity studies reported multiple, independent habitat comparisons, a total of 36 data sets were incorporated into the analyses (Appendix B). The converted habitats sampled across these studies can be categorized along a gradient of canopy openness, spanning: (1) "modified" forest with a native, closed canopy (e.g., selective logging or secondary regrowth), (2) "forested agriculture" with an open native or nonnative canopy (e.g., agroforestry and tree plantations), and (3) "non-forested agriculture," or cleared agricultural habitats (e.g., areas of annual crops, cattle pasture, and clearcuts). All studies had minimal elevation differences and used sampled dung beetles with standardized dung-baited pitfall traps across all sites. Further study selection details can be found in Nichols et al. (2007). After removing species with incomplete trait information, or from genera absent from the phylogeny, a total of 1119 observations of 265 species in 24 genera were incorporated into subsequent analyses.

\section{Trait data}

Three dung beetle traits are thought to correlate with sensitivity to forest conversion (Appendix A).

Body size in dung beetles has been positively correlated with sensitivity to tropical forest modification (Gardner et al. 2008) and fragmentation (Larsen et al. 2005). In the cooler understories of intact tropical forest, larger-bodied beetles have an advantage in fecal resource acquisition (Horgan and Fuentes 2005) and competitive outcomes (Chown and Klok 2011). Higher body temperature, however, may become a liability in modified tropical forests, where higher air and soil temperatures can push larger beetles toward their maximum sustained temperature $\left(\sim 42^{\circ} \mathrm{C}\right.$; Verdu et al. 2006, Chown and Klok 2011). Larger body size is also associated with a greater capacity for landscape-level dispersal (Larsen et al. 2008). At low levels of habitat degradation, greater vagility may translate into greater survival rates, as large species can more easily locate and access patchily distributed resources. In severely degraded habitat however, the combination of lower survival due to thermointolerance and enhanced emigration rates may drive a decline in population size and occupancy rates for larger-bodied species (Larsen et al. 2005, 2008). 
Compounding these effects, larger-bodied beetles may favor feces deposits from the larger-bodied mammals most likely to be rare in degraded tropical forests (Nichols et al. 2009).

Nesting strategy may alter the relative fitness consequences faced by larval and adult dung beetles in converted forests, as a consequence of both abiotic and biotic changes. Dung beetles provide nests and a food supply for their progeny (Halffter and Edmonds 1982). Tunneler species construct linear or branching burrows directly beneath the dung deposition site, while roller species construct shallower tunnels some distance away from the deposition site. These shallower nests of roller species are likely to be less buffered against the increased temperature and decreased humidity characteristic of converted forest (Larsen 2011). Anecdotal observations suggest that the nesting activities of rollers are influenced by the physical structure of the forest floor, and can be negatively impacted by increased leaf litter, characteristic of arid forested landscapes with slow decomposition rates.

Activity period may interact with the higher daytime temperatures and lower humidity of modified tropical forests to strongly penalize diurnal species (Daily and Ehrlich 1996, Larsen 2011). Diurnal activity is often associated with smaller body size (e.g., Feer and Pincebourde 2005, Slade et al. 2007), which may help smaller species cope with ambient nighttime temperatures too low to allow for flight initiation (Verdu et al. 2006). Conversely nocturnal species are often larger, and therefore potentially less constrained by lower night temperatures (Chown and Klok 2011), which tend to be more consistent between intact and converted habitats (Larsen 2011).

Information on species' body mass, nesting strategy, and activity period was compiled from published and unpublished sources (Appendix C). We used mean trait values collated from the literature when site-specific trait values were unavailable. For species with unknown body mass, we estimated body mass $(y)$ from body length $(x)\left(y=0.01 x^{3.28}, R^{2}=0.86\right)$ from a set of 79 species in 22 genera for which both body length and body mass data were available.

\section{Species response}

From each data set we extracted the per-trap abundance for every beetle species, from both intact forest and each forest conversion class. To quantify the difference in species before and after forest conversion, we calculated a $\log$ response ratio:

$$
\log \text { response ratio }=\ln \left(\frac{N_{\text {converted forest }}+1}{N_{\text {intact forest }}+1}\right) .
$$

Species that increased in abundance following the conversion of intact forest have positive values, species with identical abundances in intact and converted habitats have a value of 0 , and species that decreased from their original abundance or went locally extinct have negative values. As our objectives centered on understanding the traits associated with the response of forest-dwelling dung beetle species, we excluded from the data set species that were not originally detected in intact forest.

\section{Phylogeny}

A single global molecular phylogeny is available for Scarabaeine dung beetles, based upon 214 species from six biogeographical regions (Monaghan et al. 2007). As this phylogeny encompassed most of the genera, but few of the species present in our data set, we modified the phylogeny by collapsing the terminal taxa of the consensus tree into generic-level tips, and representing species phylogeny below the genus level with the addition of a single branch length unit (e.g., Bielby et al. 2008). There were no significant differences in mean body mass, diel activity, or nesting strategy frequency or mean log response ratios between the species that entered the analyses and those excluded due to poor representation in the available phylogeny.

\section{Analyses}

To explore if dung beetle population responses to forest conversion were consistent across biogeographic regions, we calculated the response ratio (Eq. 1) of each dung beetle species to the conversion of tropical forest in all converted forest classes, and compared the mean population response between the Neotropical and AfroEurasian tropical regions using a bootstrapped $t$ test.

To investigate which species' traits were associated with this population response, we conducted a phylogenetic comparative analysis across the pooled data set. We first tested for significant phylogenetic signal across the data set with Blomberg's $K$ for body mass (Blomberg et al. 2003) and the Maddison and Slatkin (1991) approach for the discrete traits of nesting strategy and activity period. Nesting strategy, though not activity period or body mass, demonstrated significant phylogenetic signal (Madison and Slatkin method, nesting strategy, $P=0.022$; activity period $P=0.082$; Bloomberg's $K$, body mass, $K=0.85, P=0.26$; Fig. 1 ).

To incorporate this lack of independence among species while accommodating multiple and discrete traits within a generalized linear modeling framework, we used the generalized estimating equation (GEE) approach as described in Paradis and Claude (2002) to model beetle abundance response as a function of three species' traits (i.e., body mass, nesting strategy, activity period), forest conversion class (i.e., intact forest, modified forest, forested agricultural habitat, or non-forested agricultural habitat), and two-way trait-habitat interactions, using a generalized linear model with Poisson errors. We accounted for phylogenetic autocorrelation by incorporating a fixed correlation matrix based on branch lengths taken from the global molecular phylogeny (Monaghan et al. 2007), and used the phylogenetic degrees of freedom to reduce the risk of inflated Type I error rates (Paradis 


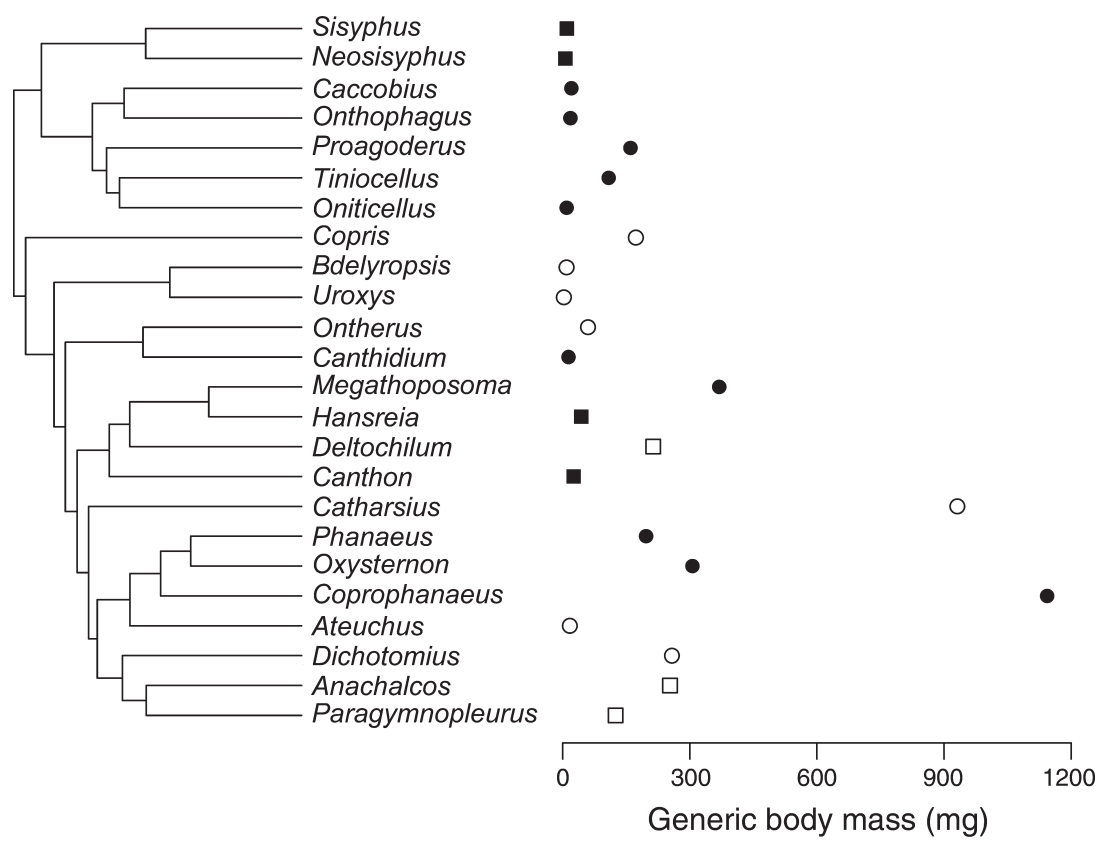

FIG. 1. Phylogenetic relationships for 24 Scarabaeine dung beetle genera, and trait information taken from a subset of 265 species. See Materials and methods for details on trait values and tree simplification, and Monaghan et al. (2007) for tree construction. The plot to the right represents the generic body mass (mean $\pm \mathrm{SE}$ ) of the species incorporated into all analyses (see Materials and methods). Symbol shape and fill reflect the dominant species trait value across all species that entered the analysis for nesting strategy (circles, tunnelers; squares, rollers) and activity period (white, nocturnal; solid, diurnal).

2006). To reduce the risk of correlation in speciesenvironment-response relationships from multiple data sets reported from a single study, we also incorporated study identity as a factor within the model. We included intact forest as the reference condition for forest conversion class, enabling the coefficients for forest conversion class to be interpreted as the average change in population response from the intact forest level. Body mass was logged and centered to the mean to facilitate interpretation. All GEE analyses were conducted using the APE package (Paradis et al. 2004) in R ( $R$ Development Core Team 2011).

Finally, we examined whether differences in traitenvironment relationships between the Neotropics (NT) and Afro-Eurasian tropics (AET) could explain regional differences in response to forest conversion. As we could not build separate models for the two regions given insufficient sample size for one trait-habitat type combination in the Afro-Eurasian data set, we used bootstrapped $t$ tests to compare the mean population response for each trait-habitat type across regions, and a Bonferroni correction to adjust the $P$ values for multiple comparisons within each trait-habitat type combination.

\section{RESUlTS}

The final pooled data set was heavily dominated by Neotropical species (NT, $n=206$; AET, $n=57$ ). Most species were nocturnal $(61 \%)$ and used a tunneling nesting strategy (74\%) (Fig. 1). Beetle body mass ranged widely $(110 \pm 14 \mathrm{mg}$, mean $\pm \mathrm{SE}, n=265$, range 1.10
$1920.75 \mathrm{mg}$ ) and was significantly higher for nocturnal (nocturnal, $171.48 \pm 260 \mathrm{mg}, n=103$; diurnal, $71.19 \pm$ $185 \mathrm{mg}, n=165 ; t_{272}=3.64, P<0.0001$, bootstrapped $95 \% \mathrm{CI}=-1.92$ to -1.72 ) as well as tunneler species (tunneler, $116.51 \pm 244 \mathrm{mg}, n=198$; roller, $91.67 \pm 142$ $\mathrm{mg}, n=70 ; t_{272}=3.64, P<0.0001$, bootstrapped $95 \% \mathrm{CI}$ $=-1.82$ to -1.78$)$. Activity period and nesting strategy were independent $\left(\chi^{2}=1.252, \mathrm{df}=1, P=0.26\right)$.

Across the pooled data set, dung beetle abundance was sharply affected by the conversion of intact tropical forest. Nearly half of all species (47\%) went locally extinct in at least one converted forest class. Over $73 \%$ of species captured in the least severe conversion class declined from their original abundance in intact forest (Fig. 2A), while $74 \%$ of species found in forested agriculture areas declined (Fig. 2B). In the most severe forest conversion class, $\sim 97 \%$ of all species declined in abundance (Fig. 2C).

Activity period and nesting strategy frequencies were distributed evenly across the fauna of the Neotropical data set, while the Afro-Eurasian tropical data set was heavily dominated by diurnal and tunneling species. Body mass was similar between regions (NT, $109.86 \pm$ $205 \mathrm{mg}$, mean $\pm \mathrm{SE}$; AET, $110.91 \pm 279 \mathrm{mg} ; t_{73}=-0.03$, $P>0.9$, bootstrapped $95 \% \mathrm{CI}=0.983$ to -2.21 ).

Are species responses to forest conversion context dependent across biogeographic regions?

Neotropical dung beetles were more sensitive to forest conversion than Afro-Eurasian tropical species across 

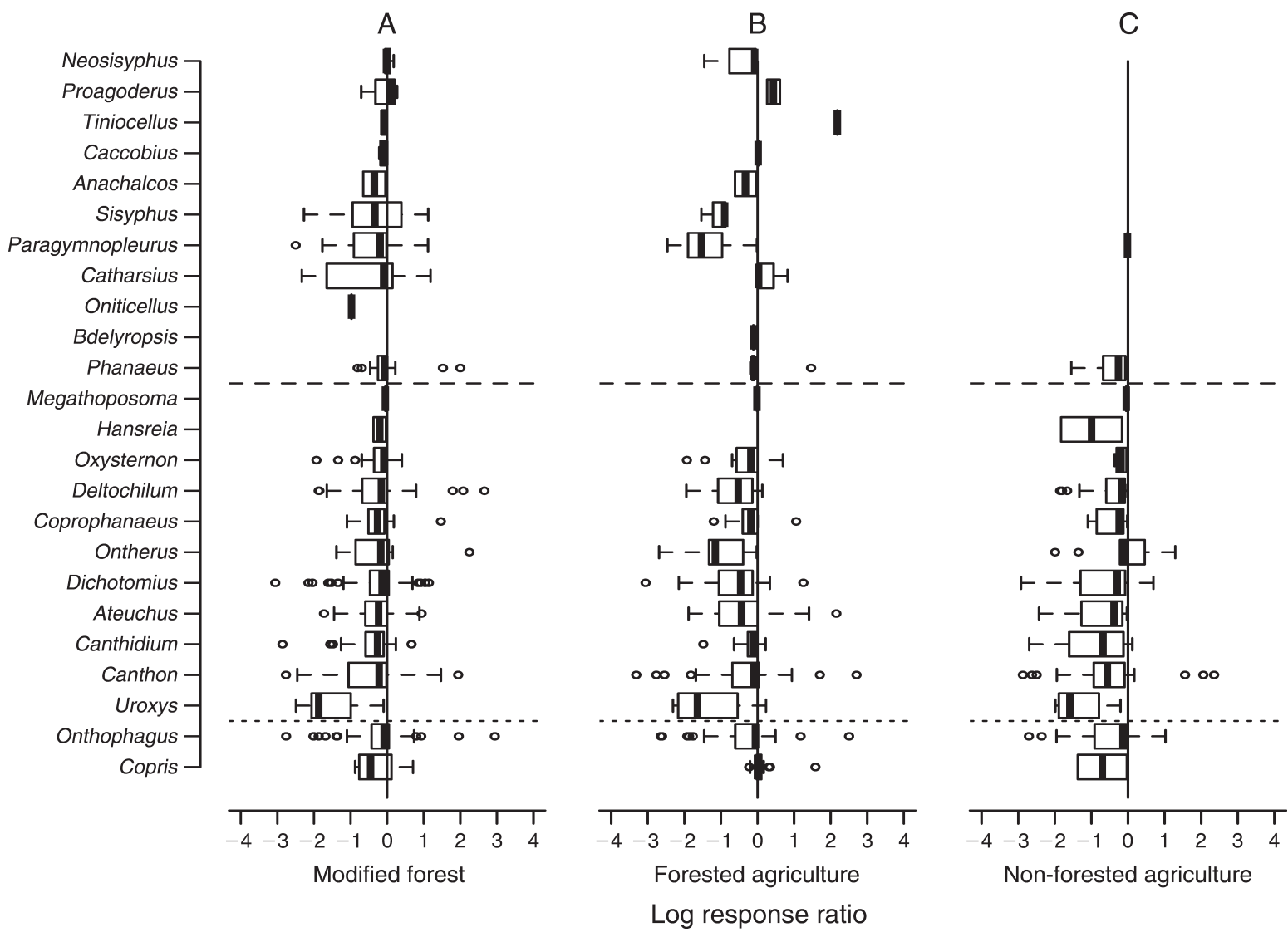

FIG. 2. Standard box and whisker plots indicating the abundance response to the conversion of lowland tropical forest to (A) modified forest, (B) forested agriculture, and (C) non-forested agriculture for 24 Scarabaeine dung beetle genera across three continents. Positive values indicate an increase in abundance following the conversion of intact forest; negative values indicate a decline in abundance following the conversion of intact forest. The dashed lines separate genera from the Afro-Eurasian tropics (above) and Neotropics (below); the dotted lines separate two genera found globally (Copris and Onthophagus). Plot whiskers indicate one standard deviation above and below mean abundance response; box outlines indicate the 25 th and 75 th percentile of abundance response; the heavy line in the box is the median; and the small open circles are outliers.

the pooled data set $(\mathrm{NT},-0.42 \pm 0.65$, mean $\pm \mathrm{SE}$; AET, $-0.21 \pm 0.51 ; t_{234}=-3.23, P=0.001$, bootstrapped $95 \% \mathrm{CI}=-0.43$ to -0.32 ). This overall effect was primarily driven by stronger declines by Neotropical beetles in non-forested agriculture $\left(t_{38}=-2.06, P=0.09\right.$, bootstrapped $95 \% \mathrm{CI}=-0.65$ to -0.42 ; Fig. $2 \mathrm{C})$, though this result should be interpreted with caution as these habitats were represented within the Afro-Eurasian tropical data set by a single study. Mean species responses to modified forest and forested agriculture were similar between regions (modified forest, $t_{135}=$ $-1.66, P=0.116$, bootstrapped $95 \% \mathrm{CI}=-0.36$ to -0.29 ; forested agriculture, $t_{77}=-0.79, P=0.438$, bootstrapped $95 \% \mathrm{CI}=-0.41$ to -0.21$)$.

\section{Which functional traits are associated with local population response to forest conversion?}

The final model explaining abundance response of dung beetles to tropical forest conversion included all the original predictor variables (Table 1, Fig. 3). Not surprisingly, population response to forest conversion was significantly affected by the severity of forest conversion (Fig. 3). The average difference in population response from the intact forest level baseline was strongest for non-forested agriculture habitats and intermediate in modified forest habitats. Species captured in forested agricultural habitats also declined in abundance from intact forest levels, although this reduction was not significant (Fig. 3).

We found significant interactions with forest conversion class for all three traits (body mass, $F_{3,1118}=9.13, P$ $<0.0001$; activity period, $F_{3,1118}=9.24, P=0.0001$; and nesting strategy, $\left.F_{3,1118}=17.54, P<0.0001\right)$. The abundance of larger-bodied beetles increased with increasing intensity of tropical forest conversion. The population responses of species with rolling or tunneling nesting strategies were highly dependent upon habitat type. Roller species suffered greater declines in abundance in forested agricultural areas but had moderately higher abundances in non-forested agricultural areas. Nocturnal species declined more severely across all 
TABLE 1. Predictors of dung beetle response to tropical forest conversion, from a phylogenetically corrected multiple linear model.

\begin{tabular}{lrrrl}
\hline \hline \multicolumn{1}{c}{ Model predictors } & Estimate & SE & $t$ & $P$ \\
\hline (Intercept) & -0.24 & 0.20 & -1.19 & 0.235 \\
Modified forest & -0.11 & 0.11 & -0.96 & 0.335 \\
Forested agriculture & 0.00 & 0.15 & -0.02 & 0.988 \\
Non-forested agriculture & -0.52 & 0.14 & -3.67 & $0.000^{*}$ \\
Body mass & 0.00 & 0.02 & 0.11 & 0.913 \\
Activity period & 0.02 & 0.04 & 0.49 & 0.627 \\
Nesting strategy & 0.00 & 0.04 & 0.07 & 0.947 \\
Modified forest $\times$ body mass & 0.08 & 0.04 & 2.06 & $0.039^{*}$ \\
Forested agriculture $\times$ body mass & 0.09 & 0.04 & 2.09 & $0.037^{*}$ \\
Non-forested agriculture $\times$ body mass & 0.12 & 0.05 & 2.44 & $0.015^{*}$ \\
Modified forest $\times$ activity period & -0.10 & 0.06 & -1.73 & 0.084 \\
Forested agriculture $\times$ activity period & -0.19 & 0.07 & -2.92 & $0.004^{*}$ \\
Non-forested agriculture $\times$ activity period & -0.09 & 0.07 & -1.28 & 0.199 \\
Modified forest $\times$ nesting strategy & -0.10 & 0.06 & -1.62 & 0.105 \\
Forested agriculture $\times$ nesting strategy & -0.24 & 0.07 & -3.38 & $0.001^{*}$ \\
Non-forested agriculture $\times$ nesting strategy & 0.10 & 0.08 & 1.26 & 0.209 \\
\hline
\end{tabular}

Notes: The model related dung beetle population response to forest conversion class, three species' traits (i.e., body mass, diel activity, and nesting strategy), and the identity of the study from which response data were taken (coefficients not shown). Significant regression coefficients are marked with an asterisk. Phylogenetic $\mathrm{df}(\mathrm{dfP})=1118$. Baseline values for human-modified habitat type, activity period, and nesting strategy were intact forest, diurnal, and tunneler, respectively.

$* P<0.05$.

conversion classes, and significantly so in forested agricultural habitats (Table 1).

\section{Do differences in trait-response relationships among biogeographical regions explain differences in population response to forest conversion?}

Several regional differences in dung beetle traitenvironment relationships may explain the observed regional context dependency in population response (Fig. 4). Diurnal Neotropical species declined more sharply than diurnal Afro-Eurasian tropical species in modified forests $(\mathrm{NT},-0.32 \pm 0.57$; AET, $-0.13 \pm 0.28$, mean $\pm \mathrm{SE} ; t_{137}=-2.12$, bootstrapped $95 \% \mathrm{CI}=-0.34$ to $-0.17, P=0.07$; Fig. 4 ), and nocturnal Neotropical species declined significantly more sharply in nonforested agricultural areas (NT, $-0.63 \pm 0.73$; AET, $-0.02 \pm 0.0, t_{65}=-1.16$, bootstrapped $95 \% \mathrm{CI}=-0.65$ to $-0.57, P<0.0001$; Fig. 4$)$. Tunneling species from the Neotropics were more sensitive than Afro-Eurasian tunneling species to conversion to all forest classes, though significantly so only in non-forested agricultural areas (modified forest, NT, $-0.34 \pm 0.49$; AET, $-0.19 \pm$
$0.40, t_{112}=-1.91$, bootstrapped $95 \% \mathrm{CI}=-0.36$ to $-0.22, P>0.05$ ) (forested agriculture, NT, $-0.33 \pm$ 0.53 ; AET, $-0.11 \pm 0.58, t_{73}=-2.06$, bootstrapped $95 \%$ $\mathrm{CI}=-0.35$ to $-0.15, P=0.06$ ) (non-forested agriculture, $\mathrm{NT},-0.65 \pm 0.72 ; \mathrm{AET},-0.16 \pm 0.27, t_{35}=-2.35$, bootstrapped $95 \% \mathrm{CI}=-0.66$ to $-0.50, P<0.0001)$. In contrast, rolling species from the Afro-Eurasian tropics performed significantly worse than Neotropical rollers in forested agricultural areas $(\mathrm{NT},-0.35 \pm 0.65$; AET, $-1.05 \pm 0.59, t_{11}=2.59$, bootstrapped $95 \% \mathrm{CI}=-0.70$ to $-0.30, P<0.0001$; Fig. 4$)$.

\section{DisCUSSION}

We found species' trait differences did explain variation in population response to forest conversion, and that the relationship between traits and population trends was greatly influenced by local and biogeographic context. In tropical land uses that retained some forest canopy there were few regional differences in the magnitude of dung beetle response. Neotropical species fared significantly worse than Afro-Eurasian tropical species in land uses that completely removed
FIG. 3. Standardized regression coefficients ( $\beta$; the $\log$ response ratios) for a phylogenetic multiple linear model relating dung beetle population response to tropical forest conversion to beetle traits and modified forest type. Responses less than zero indicate a decline in relative abundance moving from intact forest to a human-modified habitat; values above zero indicate an increase. Plot error bars represent \pm SE of the coefficient.
Food relocation strategy

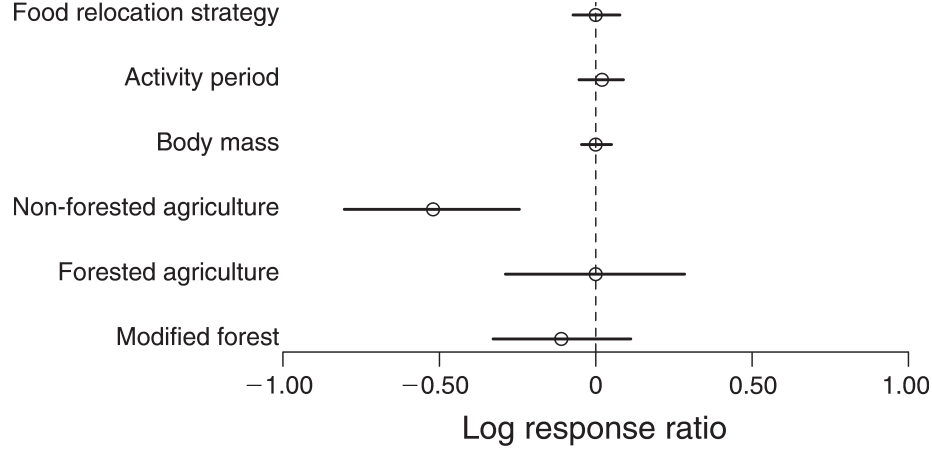



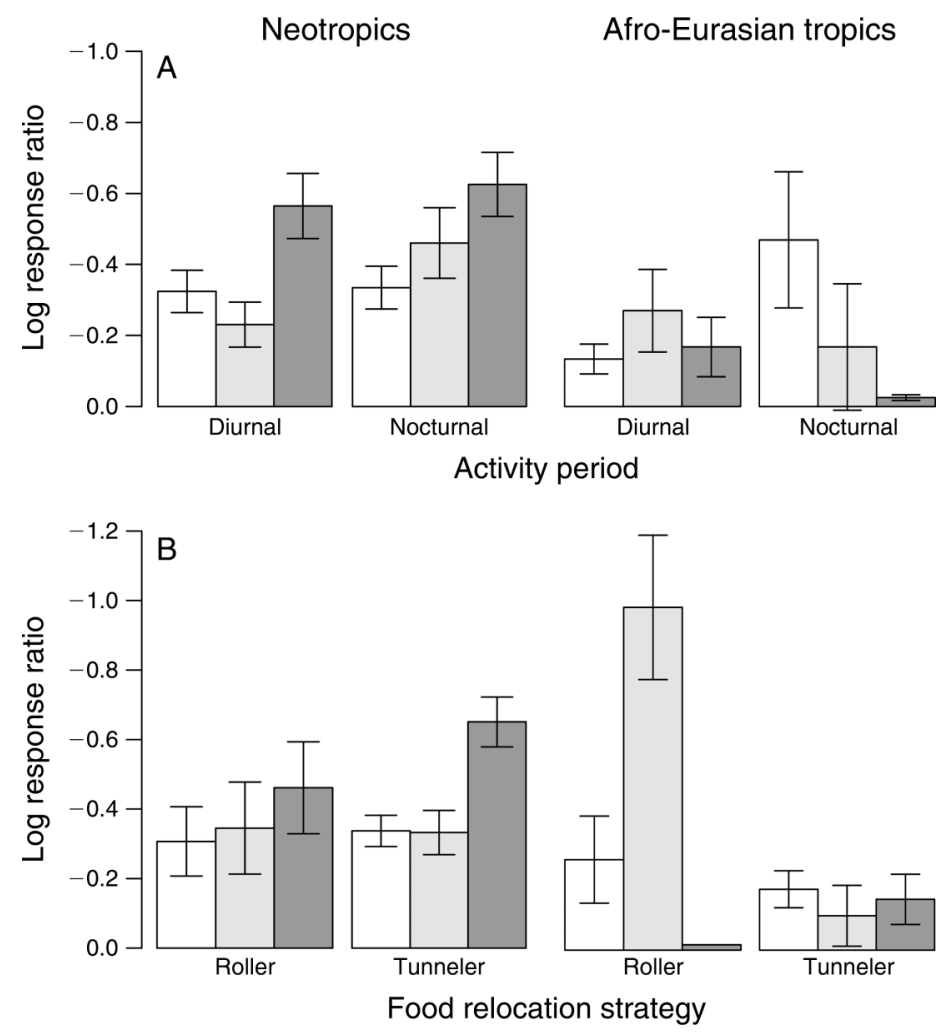

FIG. 4. Interactions between dung beetle population decline (as measured by the log response ratio), species' traits, and degree of forest conversion severity in two biogeographic regions. Three degrees of tropical forest conversion severity are represented by modified forest (open), forested agriculture (light gray), and nonforested agriculture (dark gray). Both species' traits, including (A) activity period and (B) food relocation strategy, and biogeographic region (Neotropical and Afro-Eurasian tropical) modulate beetle abundance response to tropical forest conversion. forest canopy, though this result must be interpreted with caution given the paucity of available AfroEurasian studies in open agricultural habitats. Across the pooled data set, the influence of nesting strategy on population response depended on the severity of forest conversion. Roller and tunneler species responded similarly to conversion to modified forests (e.g., selectively logged areas) and complete removal of the forest canopy (e.g., permanent agricultural areas). Yet in forested agriculture areas (e.g., timber plantations and agroforestry sites), only roller species demonstrated significant population declines. This cross-regional pattern was driven by the significantly stronger response of roller species from Afro-Eurasian tropical sites. The higher air and soil temperatures of degraded habitats may disproportionately influence rollers due to their shallower burial depth (Halffter and Edmonds 1982), as dung beetle larval survival rates can be strongly reduced at low soil moisture levels (Sowig 1995). Anedoctal evidence also suggests that increased leaf litter in forested agriculture areas may disproportionately impact the reproductive success of rollers by impeding brood ball relocation ( $\mathrm{T}$. Larsen, personal communication).

The influence of activity period on beetle population response demonstrated similar context dependency. Across the pooled data set, diurnal species were less sensitive than nocturnal species to all degrees of forest conversion, though the magnitude of this difference was only significant in forested agriculture habitats. Diurnal
Neotropical species demonstrated a significantly more negative response than nocturnal species to the conversion of intact forest into modified forests and nonforested agriculture. In the most severe class of forest conversion, the observed population decline of Neotropical species was independent of activity period, suggesting that the abiotic conditions in these areas may exceed the thermoregulatory tolerances of most species regardless of diel activity (Chown and Klok 2011).

Finally, beetle body mass was positively related to population response across all habitats, although the magnitude of this relationship was dependent upon habitat type. This finding was surprising, given that large body size is associated with a range of species' traits (e.g., lower fecundity, longer generation time; Halffter and Edmonds 1982, Chown and Gaston 2010) that theoretically reduce a population's ability to compensate for increased rates of mortality arising from unfavorable abiotic conditions (Chown and Klok 2011) and decreased food availability (Nichols et al. 2009) in modified forests. Comparable positive body massabundance relationships have been reported from comparative analyses of bird (Laurance et al. 2011, Pocock 2011) and primate (Cowlishaw et al. 2009) response to forest conversion. A potential explanation for this positive relationship maybe a size bias in capture rates in areas of resource scarcity (E. Nichols, M. Uriarte, C. Peres, J. Louzada, R. Fagundes-Braga, G. Schiffler, W. Endo, and S. Spector, unpublished manuscript). Dung beetle capture rates often increase in areas 
of reduced food availability (Burger and Petersen 1991, Horgan 2005). As highly vagile larger-bodied species beetles are able to both detect and access food from long distances, fecal resource scarcity in converted habitats may increase the representation of larger-bodied species in baited pitfall trap data. Disentangling the potential role of this sampling artifact from a true body massabundance relationship will be necessary to determine the implications of body size on dung beetle population response.

While we have emphasized the role of species' traits in governing response to abiotic environmental change, shifting biotic interactions are also likely to strongly influence beetle response to tropical forest conversion. For example, tropical land use change impacts vertebrate communities through its combined impacts on food resource availability (Parry et al. 2007) and human hunting (Parry et al. 2009), presumably with severe consequences on beetle reproductive success in converted habitats (Nichols et al. 2009). The limited data on dung beetle predation suggests that predation rates by avifauna (Horgan and Berrow 2004) and rodents (Larsen et al. 2008) may be high, though how these interactions are influenced by changing tropical land cover remains unstudied. Examination of how biotic interactions are influenced by forest conversion and which species' traits leverage these effects is an important challenge for animal comparative analyses. In particular diet breadth and plasticity consistently emerge as important predictors of response across many animal taxa, e.g., butterflies (Diamond et al. 2011), Passeriforme birds (Angert et al. 2011), and bees (Bommarco et al. 2010), yet remain poorly characterized for dung beetles (Nichols et al. 2009).

The regional differences in both population response to forest conversion and trait-population trend relationships observed here are also consistent with the extinction filter hypothesis, where contemporary biotic responses to environmental change are conditioned by historical processes (Turvey and Fritz 2011). Late Pleistocene shifts in the areal extent of forest and savanna areas across the Afrotropics have been proposed as a mechanism for the limited number of Afrotropical forest-obligate genera and comparatively low diversity within those genera (Scholtz et al. 2009). In Southeast Asia, similar forest-savanna dynamics arose due to interactions between climate and sea levels (Heaney 1991). In contrast, these same glacial cycles acted to largely maintain Neotropical lowland forest under continuous forest cover (Colinvaux et al. 2000), exposing fewer American dung beetle genera to openformation vegetation across their evolutionary history (Scholtz et al. 2009). These changes may have increased the sensitivity of modern forest-dwelling Neotropical dung beetle fauna to contemporary forest conversion, relative to Afrotropical or Southeast Asian taxa.

Predicting species vulnerability to anthropogenic environmental change is essential for avoiding or mitigating future species loss. This will depend equally on our ability to distinguish between uninformative species' traits and unsuccessful associations between traits, environmental change, and response. Ultimately, this will require quantifying relevant functional trait information across large numbers of species and sites (Angert et al. 2011). As for many animal taxa, community-wide morphological, physiological, and phenological (M-P-P) traits of dung beetles are nearly nonexistent. In this study we used a set of "proxy" species' traits selected for their availability rather than their explicit relationship to fitness. When such proxy traits represent such a "one-to-many" relationship with functional traits more explicitly related to fitness, unambiguous trait-environment-response associations could be expected to be rare.

This study contributes to mounting evidence suggesting that intrinsic species' traits do not influence the response of organisms to environmental change in isolation, but rather when coupled with habitat characteristics and biogeographic history (Isaac and Cowlishaw 2004, Cowlishaw et al. 2009, Angert et al. 2011, Collen et al. 2011, Pocock 2011, Ernst et al. 2012). The identification of such context dependency is particularly crucial if the results of comparative studies are to be incorporated into conservation decision-making and policy (Cardillo and Meijaard 2012). Further effort is needed to develop a robust framework to refine our understanding of the roles of context dependency and trait quality on observed species' response to environmental change.

\section{AcKNOWLEDGments}

This manuscript was fostered by the Scarabaeinae Research Network (National Science Foundation Grant Number DEB0043443). Any opinions, findings, and conclusions or recommendations expressed in this material are those of the authors and do not necessarily reflect the views of the National Science Foundation. E. Nichols acknowledges funding from a Columbia University Faculty Fellowship. F. Z. Vaz-de-Mello, J. Louzada, E. Nichols, and S. H. Spector acknowledge support from the Brazilian Conselho Nacional de Desenvolvimento Científico e Tecnológico (CNPq). F. Z. Vaz-de-Mello acknowledges support by the Fundação de Amparo à Pesquisa do Estadode, Mato Grosso, Brazil. K. Vulinec acknowledges support from the Fulbright Scholar Program.

\section{Literature Cited}

Angert, A. L., L. G. Crozier, L. J. Rissler, S. E. Gilman, J. J. Tewksbury, and A. J. Chunco. 2011. Do species' traits predict recent shifts at expanding range edges? Ecology Letters 14:677-689.

Balmford, A. 1996. Extinction filters and current resilience: the significance of past selection pressures for conservation biology. Trends in Ecology and Evolution 11:193-196.

Bielby, J., N. Cooper, A. A. Cunningham, T. W. J. Garner, and A. Purvis. 2008. Predicting susceptibility to future declines in the world's frogs. Conservation Letters 1:82-90.

Blomberg, S. P., T. Garland, and A. R. Ives. 2003. Testing for phylogenetic signal in comparative data: behavioral traits are more labile. Evolution 57:717-745.

Bommarco, R., J. C. Biesmeijer, B. Meyer, S. G. Potts, J. Poyry, S. P. M. Roberts, I. Steffan-Dewenter, and E. 
Ockinger. 2010. Dispersal capacity and diet breadth modify the response of wild bees to habitat loss. Proceedings of the Royal Society B 277:2075-2082.

Burger, B. V., and W. G. B. Petersen. 1991. Semiochemicals of the Scarabaeinae. III. Identification of an attractant for the dung beetle Pachyolomerus femoralis in the fruit of the spineless monkey orange tree Strychnos madagascariensis. Zeitschrift für Naturforschung 46c:1073-1079.

Cardillo, M., G. M. Mace, J. L. Gittleman, K. E. Jones, J. Bielby, and A. Purvis. 2008. The predictability of extinction: biological and external correlates of decline in mammals. Proceedings of the Royal Society B 275:1441-1448.

Cardillo, M., and E. Meijaard. 2012. Are comparative studies of extinction risk useful for conservation? Trends in Ecology and Evolution 27:167-171.

Chown, S. L., and K. J. Gaston. 2010. Body size variation in insects: a macroecological perspective. Biological Reviews 85:139-169.

Chown, S. L., and C. J. Klok. 2011. The ecological implications of physiological diversity in dung beetles. Pages 200-219 in L. W. Simmons and T. J. Ridsdill-Smith, editors. Ecology and evolution of dung beetles. Wiley-Blackwell, New York, New York, USA.

Colinvaux, P. A., P. E. De Oliveira, and M. B. Bush. 2000 Amazonian and neotropical plant communities on glacial time-scales: the failure of the aridity and refuge hypotheses. Quaternary Science Reviews 19:141-169.

Collen, B., L. McRae, S. Deinet, A. De Palma, T. Carranza, N. Cooper, J. Loh, and J. E. M. Baillie. 2011. Predicting how populations decline to extinction. Philosophical Transactions of the Royal Society B 366:2577-2586.

Cowlishaw, G., R. A. Pettifor, and N. J. B. Isaac. 2009. High variability in patterns of population decline: the importance of local processes in species extinctions. Proceedings of the Royal Society B 276:63-69.

Daily, G., and P. Ehrlich. 1996. Nocturnality and species survival. Proceedings of the National Academy of Sciences USA 93:11709-11712.

Diamond, S. E., A. M. Frame, R. A. Martin, and L. B. Buckley. 2011. Species' traits predict phenological responses to climate change in butterflies. Ecology 92:1005-1012.

Ernst, R., A. Keller, G. Landburg, T. U. Grafe, K. E. Linsenmair, M. O. Rodel, and F. Dziock. 2012. Common ancestry or environmental trait filters: cross-continental comparisons of trait-habitat relationships in tropical anuran amphibian assemblages. Global Ecology and Biogeography 21:704-715.

Feer, F., and S. Pincebourde. 2005. Diel flight activity and ecological segregation within an assemblage of tropical forest dung and carrion beetles. Journal of Tropical Ecology 21:2130 .

Fisher, D. O., and I. P. F. Owens. 2004. The comparative method in conservation biology. Trends in Ecology and Evolution 19:391-398.

Fritz, S. A., O. R. P. Bininda-Emonds, and A. Purvis. 2009. Geographical variation in predictors of mammalian extinction risk: big is bad, but only in the tropics. Ecology Letters 12:538-549.

Gardner, T. A., M. I. M. Hernandez, J. Barlow, and C. A. Peres. 2008. Understanding the biodiversity consequences of habitat change: the value of secondary and plantation forests for neotropical dung beetles. Journal of Applied Ecology 45:883-893.

Halffter, G., and W. D. Edmonds. 1982. The nesting behavior of dung beetles (Scarabaeinae): an ecological and evolutive approach. Institúto de Ecología, México, D. F.

Heaney, L. R. 1991. A synopsis of climatic and vegetational change in Southeast Asia. Climatic Change 19:53-61.

Horgan, F. G., and S. Berrow. 2004. Hooded crow foraging from dung pats: implications for the structure of dung beetle assemblages. Biology and Environment: Proceedings of the Royal Irish Academy 104B:119-124.

Horgan, F. G., and R. C. Fuentes. 2005. Asymmetrical competition between Neotropical dung beetles and its consequences for assemblage structure. Ecological Entomology 30:182-193.

Isaac, N. J. B., and G. Cowlishaw. 2004. How species respond to multiple extinction threats. Proceedings of the Royal Society B 271:1135-1141.

Larsen, T. H. 2011. Upslope range shifts of Andean dung beetles in response to deforestation: compounding and confounding effects of microclimatic change. Biotropica 44:82-89.

Larsen, T. H., A. Lopera, and A. Forsyth. 2008. Understanding trait-dependent community disassembly: dung beetles, density functions and forest fragmentation. Conservation Biology 22:1288-1298.

Larsen, T. H., N. Williams, and C. Kremen. 2005. Extinction order and altered community structure rapidly disrupt ecosystem functioning. Ecology Letters 8:538-547.

Laurance, W. F., et al. 2011. Global warming, elevational ranges and the vulnerability of tropical biota. Biological Conservation 144:548-557.

Lee, T. M., and W. Jetz. 2011. Unravelling the structure of species extinction risk for predictive conservation science. Proceedings of the Royal Society B 278:1329-1338.

Maddison, W. P., and M. Slatkin. 1991. Null models for the number of evolutionary steps in a character on a phylogenetic tree. Evolution 45:1184-1197.

Monaghan, M. T., D. J. G. Inward, T. Hunt, and A. P. Vogler. 2007. A molecular phylogenetic analysis of the Scarabaeinae (dung beetles). Molecular Phylogenetics and Evolution 45:674-692.

Nichols, E., T. A. Gardner, C. A. Peres, and S. Spector. 2009. Co-declining mammals and dung beetles: an impending ecological cascade. Oikos 118:481-487.

Nichols, E., T. Larsen, S. Spector, A. L. Davis, F. Escobar, M. Favila, and K. Vulinec. 2007. Global dung beetle response to tropical forest modification and fragmentation: a quantitative literature review and meta-analysis. Biological Conservation 137:1-19.

Nichols, E., S. Spector, J. Louzada, T. Larsen, S. Amezquita, M. Favila, and T. S. R. Network. 2008. Ecological functions and ecosystem services of Scarabaeine dung beetles: a review. Biological Conservation 141:1461-1474.

Nylin, S., and A. Bergstrom. 2009. Threat status in butterflies and its ecological correlates: How far can we generalize? Biodiversity and Conservation 18:3243-3267.

Paradis, E. 2006. Analysis of phylogenetics and evolution with R. Springer, New York, New York, USA.

Paradis, E., and J. Claude. 2002. Analysis of comparative data using generalized estimating equations. Journal of Theoretical Biology 218:175-185.

Paradis E., J. Claude, and K. Strimmer. 2004. APE: analyses of phylogenetics and evolution in $\mathrm{R}$ language. Bioinformatics 20:289-290.

Parry, L., J. Barlow, and C. A. Peres. 2007. Large-vertebrate assemblages of primary and secondary forests in the Brazilian Amazon. Journal of Tropical Ecology 23:653-662.

Parry, L., J. Barlow, and C. A. Peres. 2009. Hunting for sustainability in tropical secondary forests. Conservation Biology 23:1270-1280.

Pocock, M. J. O. 2011. Can traits predict species' vulnerability? A test with farmland passerines in two continents. Proceedings of the Royal Society B 278:1532-1538.

R Development Core Team. 2011. R: a language and environment for statistical computing. R Foundation for Statistical Computing, Vienna, Austria.

Scholtz, C., A. Davis, and U. Kryger. 2009. Outlines of composition, spatial pattern, and hypothetical origins of regional dung beetle fauna. Pages 366-385 in C. Scholtz, A. 
Davis, and U. Kryger, editors. Evolutionary biology and conservation of dung beetles. Pensoft, Sofia, Bulgaria.

Slade, E. M., D. J. Mann, J. F. Villanueva, and O. T. Lewis. 2007. Experimental evidence for the effects of dung beetle functional group richness and composition on ecosystem function in a tropical forest. Journal of Animal Ecology 76:1094-1104.

Sowig, P. 1995. Habitat selection and offspring survival rate in three paracoprid dung beetles: the influence of soil type and soil moisture. Ecography 18:147-154.

Turvey, S. T., and S. A. Fritz. 2011. The ghosts of mammals past: biological and geographical patterns of global mam- malian extinction across the Holocene. Philosophical Transactions of the Royal Society B 366:2564-2576.

Verdu, J. R., L. Arellano, and C. Numa. 2006. Thermoregulation in endothermic dung beetles (Coleoptera: Scarabaeidae): effect of body size and ecophysiological constraints in flight. Journal of Insect Physiology 52:854-860.

Yackulic, C. B., E. W. Sanderson, and M. Uriarte. 2011. Anthropogenic and environmental drivers of modern range loss in large mammals. Proceedings of the National Academy of Sciences USA 108:4024-4029.

\section{Supplemental Material}

\section{Appendix A}

Results of previous investigations of dung beetle species' trait correlates of response to the fragmentation or modification of moist tropical forests, using non-phylogenetically corrected analyses (Ecological Archives E094-015-A1).

\section{Appendix B}

Description of the original data used in phylogenetically corrected comparative analyses to quantify the trait correlates of beetle population response to tropical forest degradation (Ecological Archives E094-015-A2).

\section{Appendix C}

Table of trait values for 265 species of Scarabaeine dung beetles incorporated into phylogenetically corrected comparative analyses to understand the trait correlates of population response to tropical forest degradation (Ecological Archives E094-015-A3). 